\title{
Cardiovascular risk factors among high-risk individuals attending the general practice at king Abdulaziz University hospital: a cross-sectional study
}

\author{
Ranya A. Ghamri ${ }^{*}$ D, Nada S. Alzahrani, Amal M. Alharthi, Hana J. Gadah, Bayan G. Badoghaish and
} Azzah A. Alzahrani

\begin{abstract}
Background: Cardiovascular disease (CVD) is the primary cause of death worldwide, accounting for $31.0 \%$ of all deaths and more than 18 million deaths annually. The 2008 World Health Report indicated that 144 (35\%) of the 413 deaths per 100,000 in 2002 in the Kingdom of Saudi Arabia (KSA) were due to CVD. Primary prevention is an important focus of most of the cardiovascular prevention guidelines around the world. In this study, we aimed to describe the prevalence of extrinsic risk factors for CVDs in a high-risk population attending general practice in Jeddah, KSA.

Methods: We conducted a cross-sectional survey at King Abdulaziz University Hospital in Jeddah. Patients started on lipid-lowering and/or antihypertensive and/or antidiabetes treatments without a history of established cardiovascular disease were interviewed. The questionnaire was adopted from the EUROASPIRE III study.

Results: Two hundred and fifty high-risk individuals ( $80.0 \%$ female) were interviewed. Overall, $72 \%$ of the patients had been diagnosed with hypertension, $61.2 \%$ of patients had dyslipidemia, and approximately two-thirds of patients had diabetes mellitus. Most of the patients (88\%) were non-smokers. The mean waist circumference of patients was $101.6 \pm 14.1 \mathrm{~cm}$, which suggests most were clinically obese. About $54.8 \%$ of the patients followed an unhealthy diet and $52.0 \%$ were physically inactive. There were significant differences between women and men in relation to dyslipidemia $(p=0.007)$, unhealthy diet $(p=0.034)$, being overweight $(p=0.018)$, and high blood cholesterol ( $p=0.002)$. We observed significantly greater prevalence of hypertension $(p=0.073)$, unhealthy diet ( $p=0.015)$, being overweight $(p=0.018)$, and high blood cholesterol $(p=0.000)$ in those patients with dyslipidemia.

Conclusion: Our study presents novel findings in the KSA. Women were more likely to have high-risk CVD risk factors compared with their male counterparts in this sample. Gender-specific prevention programs in the KSA should be considered to more appropriately target at-risk individuals, to reduce preventable morbidity and mortality associated with CVDs.
\end{abstract}

Keywords: Cardiovascular, Prevention, Lifestyle, Cardiovascular risk factors, Primary prevention

\footnotetext{
* Correspondence: raghamri@kau.edu.sa

Department of Family Medicine, Faculty of Medicine, King Abdulaziz

University, P.O. Box: 42806, Jeddah, 21551 Jeddah, Kingdom of Saudi Arabia
}

(c) The Author(s). 2019 Open Access This article is distributed under the terms of the Creative Commons Attribution 4.0 International License (http://creativecommons.org/licenses/by/4.0/), which permits unrestricted use, distribution, and reproduction in any medium, provided you give appropriate credit to the original author(s) and the source, provide a link to the Creative Commons license, and indicate if changes were made. The Creative Commons Public Domain Dedication waiver (http://creativecommons.org/publicdomain/zero/1.0/) applies to the data made available in this article, unless otherwise stated. 


\section{Background}

Cardiovascular diseases (CVDs) include coronary heart disease (CHD), cerebrovascular disease, peripheral arterial disease, rheumatic heart disease, congenital heart disease, deep vein thrombosis, and pulmonary embolism [1, 2]. CVD is the primary cause of death worldwide, accounting for $31.0 \%$ of all deaths [3] and $>18$ million deaths annually $[4,5]$. The majority of these deaths occur in low- and middle-income countries [6]. Considerable efforts have been made in high-income countries to define, identify and modify risk factors for CVD in order to develop treatments that promote an age-adjusted decline in CVD mortality $[4,6]$. Although a significant proportion of extrinsic risk factors for CVD (such as cigarette smoking, unhealthy diet, and physical inactivity) are preventable, the incidence of CVDs continues to increase because of inadequate prevention measures $[7,8]$. Consequently, $>23$ million people are projected to die annually from CVD by $2030[4,9]$.

According to the latest World Health Organization (WHO) statistics, chronic, noncommunicable diseases account for the majority of fatalities in the Kingdom of Saudi Arabia (KSA) [10, 11]. The 2008 World Health Report indicated that 144 (35\%) of the 413 deaths per 100,000 in 2002 in KSA were due to CVD [10, 11]. CHD represents the third most common cause of hospitalbased mortality, behind road traffic accidents and senility $[6,12]$. CHD has also been attributed to the increasing and high prevalence of the aforementioned risk factors $[6,13]$. An increase in sedentary behavior is likely to be an important driver of CVDs in the KSA [14]. Furthermore, there is a significant proportion of the population with hypertension, a risk factor that contributes significantly to CVD [15].

Studies have shown that primary prevention for people without established CVD is as important as secondary prevention $[16,17]$. Indeed, primary prevention is an important focus of most of the cardiovascular prevention guidelines around the world [18-20]. We are not aware of any studies that have focused on CVD risk factors in high-risk individuals in the KSA. Thus, here, we aimed to describe the prevalence of extrinsic risk factors for CVDs in a high-risk population attending general practice in Jeddah, KSA.

\section{Methods}

\section{Ethical approval}

This study was approved by Biomedical Ethics Committee of King Abdulaziz University (Reference No. 32217). Written consent was obtained from all participants before the interview.

\section{Study design and area}

We conducted a cross-sectional survey at King Abdulaziz University Hospital (KAUH) in Jeddah, the second largest city in Saudi Arabia after the capital city, Riyadh. We selected a random sample of 250 patients attending the General Practice at KAUH. The inclusion criteria were: male and female patients aged $>40$ years and currently on antihypertensive and/or lipid-lowering and/or anti-diabetes drug treatment regimens. The exclusion criteria were: patients with established cardiovascular disease (i.e., previous myocardial infarction, unstable angina, stable angina, stroke, peripheral arterial disease, or another atherosclerotic disease).

\section{Data collection}

Data were collected using both anonymous interviewadministered questionnaires and physical measurements. The questionnaire was adopted from the EUROASPIRE III study [21] and modified by the researchers. Interviews were conducted by the researchers during hospital working hours. The questionnaire comprised four main sections: (1) personal and demographic details; (2) lifestyle and other risk factors related to smoking, diet, exercise, blood pressure, lipids and glucose; (3) lifestyle changes adopted by the patient over the last 3 years; (4) medications and family history (in patients with premature coronary heart disease). Then, measurements of height, weight, waist circumference, blood pressure, and heart rate were taken. Blood pressure was measured once by a trained nurse on the right or left upper arm in a sitting position using an OMRON automatic sphygmomanometer M5-1. The questionnaire is shown in Additional files 1.

\section{Statistical analysis}

The statistical analysis in this research was performed using SPSS, version 21.0 (IBM, NY, USA). Descriptive statistics such as frequency, percentage, mean, and standard deviation were used to describe the data. A Mann-Whitney test was performed to analyze nonparametric differences in the risk factors for CVD among men and women. A $p$-value $<0.05$ was regarded as statistically significant.

\section{Results}

\section{Demographic and physical characteristics}

The demographic characteristics of the 250 patients are shown in Table 1 . The mean age of patients was $59.7 \pm$ 11.3 years. The male:female ratio was $1: 4$ (50:200). Approximately one-third of patients had no formal schooling, while 16.4 and $16.8 \%$ of patients had attended primary and secondary school, respectively. Approximately one-third of the patients were unemployed, while one-third spent most of their time at home. Only 31 (12.4\%) were still working full-time. The mean height of the patients was $155.3 \pm 17.3 \mathrm{~cm}$ and the mean weight was $76.4 \pm 16.2 \mathrm{~kg}$. The mean waist circumference was 
Table 1 Demographic and physical characteristics of the

\begin{tabular}{|c|c|}
\hline Characteristics & $\begin{array}{l}\text { Number }(\%) \\
\text { or Mean } \pm \text { Standard } \\
\text { Deviation }\end{array}$ \\
\hline Age (years) & $59.7 \pm 11.3$ \\
\hline \multicolumn{2}{|l|}{ Gender } \\
\hline Male & $50(20 \%)$ \\
\hline Female & $200(80 \%)$ \\
\hline \multicolumn{2}{|l|}{ Level of Education } \\
\hline No Formal Schooling & $76(30.8 \%)$ \\
\hline Less than Primary School & $12(4.9 \%)$ \\
\hline Primary School Completed & $41(16.7 \%)$ \\
\hline Secondary School Completed & $42(17.1 \%)$ \\
\hline High School Completed & $30(12.2 \%)$ \\
\hline $\begin{array}{l}\text { Intermediate between Secondary } \\
\text { Levels }\end{array}$ & $7(2.8 \%)$ \\
\hline College Completed & $30(12.2 \%)$ \\
\hline Post-Graduate Degree & $8(3.3 \%)$ \\
\hline \multicolumn{2}{|l|}{ Job } \\
\hline Full-Time Employed & $31(12.8 \%)$ \\
\hline Part-Time Employed & $5(2.1 \%)$ \\
\hline Unemployed & $85(35 \%)$ \\
\hline House Person & $80(32.8 \%)$ \\
\hline Retired & $42(17.3 \%)$ \\
\hline \multicolumn{2}{|l|}{ Reason for retirement } \\
\hline Age Related & $22(57.9 \%)$ \\
\hline Other Illness & $4(10.5 \%)$ \\
\hline Personal Choice & $12(31.6 \%)$ \\
\hline Height (cm) & $155.3 \pm 17.3$ \\
\hline Weight (kg) & $76.4 \pm 16.2$ \\
\hline Waist (cm) & $101.6 \pm 14.1$ \\
\hline Body Mass Index $\left(\mathrm{kg} / \mathrm{m}^{2}\right)$ & $31.24 \pm 6.35$ \\
\hline Measurement of Systolic BP (mmHg) & $139.7 \pm 18.1$ \\
\hline Measurement of Diastolic BP (mmHg) & $71.9 \pm 12.1$ \\
\hline $\begin{array}{l}\text { Measurement of Resting Heart Rate } \\
\text { (bpm) }\end{array}$ & $79.5 \pm 14.4$ \\
\hline
\end{tabular}

$101.6 \pm 14.1 \mathrm{~cm}$, which suggests most of the patients were clinically obese. The mean systolic blood pressure level was $139.7 \pm 18.1$ and the mean diastolic blood pressure level was $71.9 \pm 12.1$. The mean resting heart rate of the patients was $79.5 \pm 14.4 \mathrm{bpm}$.

\section{Prevalence of relevant CVD risk factors}

As shown in Tables 2, 180 (72\%) of the patients had been diagnosed with hypertension with a mean disease duration of $7.9 \pm 6.7$ years; $153(61.2 \%)$ of patients had dyslipidemia with a mean duration of $6.8 \pm 5.8$ years. Approximately two-thirds of patients had diabetes mellitus
Table 2 Relevant CVD Risk Factors

\begin{tabular}{|c|c|}
\hline Factors & $\begin{array}{l}\text { Number }(\%) \\
\text { or Mean } \pm \text { Standard } \\
\text { Deviation }\end{array}$ \\
\hline History of Hypertension & $180(72 \%)$ \\
\hline Duration of Hypertension (Years) & $7.87 \pm 6.68$ \\
\hline History of Dyslipidemia & $153(61.2 \%)$ \\
\hline Duration of Dyslipidemia (Years) & $6.84 \pm 5.83$ \\
\hline History of Diabetes & $172(68.8 \%)$ \\
\hline Duration of Diabetes (Years) & $10.75 \pm 7.90$ \\
\hline \multicolumn{2}{|l|}{ Smoking } \\
\hline Smoker & $17(6.8 \%)$ \\
\hline Non-smoker & $220(88 \%)$ \\
\hline Former smoker & $13(5.2 \%)$ \\
\hline \multicolumn{2}{|l|}{ Diet/Body Weight Issues } \\
\hline Informed about Unhealthy diet & $137(54.8 \%)$ \\
\hline Informed about being Overweight & $133(53.2 \%)$ \\
\hline Trying to Lose Weight & $140(56 \%)$ \\
\hline Long-Standing IIIness & $114(45.8 \%)$ \\
\hline \multicolumn{2}{|l|}{ Activity Level } \\
\hline No Weekly Physical Activity & $130(52 \%)$ \\
\hline Only Light Physical Activity in Most Weeks & $85(34 \%)$ \\
\hline $\begin{array}{l}\text { Vigorous Physical Activity Once or Twice a } \\
\text { Week }\end{array}$ & $21(8.4 \%)$ \\
\hline $\begin{array}{l}\text { Vigorous Physical Activity Three or More } \\
\text { Times a Week }\end{array}$ & $11(4.4 \%)$ \\
\hline Don't Know/ Unsure & $3(1.2 \%)$ \\
\hline \multicolumn{2}{|l|}{ Blood Pressure } \\
\hline Informed about High Blood Pressure & $185(74 \%)$ \\
\hline $\begin{array}{l}\text { Taking Medicine Prescribed to Lower Blood } \\
\text { Pressure }\end{array}$ & $181(86.6 \%)$ \\
\hline $\begin{array}{l}\text { Following a Special Diet to Lower Blood } \\
\text { Pressure }\end{array}$ & $90(43.1 \%)$ \\
\hline Self-Monitoring of Blood Pressure & $88(45.1 \%)$ \\
\hline \multicolumn{2}{|l|}{ Cholesterol } \\
\hline Informed about High Blood Cholesterol & $179(71.6 \%)$ \\
\hline $\begin{array}{l}\text { Following a Special Diet to Lower Blood } \\
\text { Cholesterol }\end{array}$ & $111(52.4 \%)$ \\
\hline \multicolumn{2}{|l|}{ Diabetes } \\
\hline Informed about Diabetes & $172(69.9 \%)$ \\
\hline \multicolumn{2}{|l|}{ Diabetes } \\
\hline \multicolumn{2}{|l|}{ Treatment } \\
\hline Diet & $2(1.1 \%)$ \\
\hline Insulin & $27(15.5 \%)$ \\
\hline Oral anti-diabetic drugs & 145 (83.3\%) \\
\hline Self-Monitoring of Blood Glucose & $113(63.8 \%)$ \\
\hline
\end{tabular}


with mean disease duration of $10.75 \pm 7.9$ years. In this cohort, most of the patients (88\%) had never smoked (Table 2). Approximately half the patients had been informed by a healthcare professional that their diet was unhealthy and that they were overweight. One hundred and forty (56\%) of the patients claimed that they were actively trying to lose weight, although light physical activity was the most prevalent form of activity (34\%). As a limitation to undertaking physical activity, 114 (45.8\%) of the patients experienced long-standing illness, disability, or infirmity.

Most of the patients $(185,74 \%)$ had been informed by a healthcare professional that they had high blood pressure and 181 were taking drugs specifically prescribed to lower their blood pressure. Ninety (43.1\%) patients were following a special diet prescribed by a healthcare professional to lower their blood pressure level. One hundred and seventy-nine (71.6\%) of the patients had been informed by a healthcare professional that they had high blood cholesterol and 111 (52.4\%) were following a special diet prescribed by a healthcare professional to lower their blood cholesterol level. One hundred and seventytwo (69.9\%) of the patients had been informed by a healthcare professional that they had diabetes mellitus. The treatment methods for diabetes varied among patients, with oral anti-diabetic drugs $(83.3 \%)$ being the most commonly used treatment regimen.

\section{Perception of future CHD risk}

Table 3 shows the perceptions and attitudes of the patients concerning their potential risk of CHD; 92 (37.7\%) of the patients were worried that they may develop CHD, 81 (32.9\%) were neutral, and 73 (29.7\%) were not worried. Around half (49.2\%) of the patients believed that their risk of developing CHD in the next 10 years was greater than for a person of the same age and sex,

Table 3 Patient Perceptions of Potential Risks of CHD

\begin{tabular}{ll}
\hline Attitude & $\begin{array}{c}\text { Number (\%) } \\
\text { or Mean } \pm \text { Standard Deviation }\end{array}$ \\
\hline Worried about Developing CHD & \\
Strongly Disagree & $44(17.9 \%)$ \\
Disagree & $29(11.8 \%)$ \\
Neutral & $81(32.9 \%)$ \\
Agree & $40(16.3 \%)$ \\
Strongly Agree & $52(21.1 \%)$ \\
Risk Perception of CHD in the Next 10 Years \\
Much Higher & $82(33.6 \%)$ \\
Higher & $38(15.6 \%)$ \\
About the Same & $105(43 \%)$ \\
Lower & $12(4.9 \%)$ \\
Much Lower & $7(2.9 \%)$ \\
\hline
\end{tabular}

while 105 (43\%) were neutral, and 19 (7.8\%) did not believe they had an increased likelihood of CHD compared to an age- and gender-matched peer.

\section{Family history of CVD}

Family history of CVD was investigated and is reported in Table 4; $27(10.8 \%)$ of the patients in this cohort had a family history of CVD, which was mostly present in brothers (37.1\%) and mothers (31.4\%). The mean age of being diagnosed with a CVD in those relatives was $47.3 \pm 16.8$ years. Eleven of the patients' relatives died due to a CVD; the mean age of death from CVD in those relatives was $66.4 \pm 9.1$ years.

\section{Comparison of CVD risk factors by gender}

The differences in CVD risk factors between men and women are shown in Table 5 . There were significant differences between men and women in relation to dyslipidemia $(p=0.007)$, unhealthy diet $(p=0.034)$, being overweight $(p=0.018)$, and high blood cholesterol $(p=$ $0.002)$; women were more likely to have the aforementioned CVD risk factors compared with their male counterparts in this sample.

\section{Differences in CVD risk factors in patients with hypertension, dyslipidemia and diabetes}

We explored whether there were differences in CVD risk factors among patients with hypertension, dyslipidemia, and diabetes (Table 6). We observed significantly greater prevalence of hypertension $(p=0.073)$, unhealthy diet $(p=0.015)$, being overweight $(\mathrm{p}=0.018)$, and high blood cholesterol $(p=0.000)$ in those patients with dyslipidemia. Furthermore, we also determined that those patients without diabetes were significantly more likely to have been diagnosed with hypertension $(p=0.001)$ compared with diabetic patients.

Table 4 Patient Family Histories with Risk Factors for CVDs

\begin{tabular}{ll}
\hline Family History & $\begin{array}{l}\text { Number (\%) } \\
\text { or Mean } \pm \text { Standard Deviation }\end{array}$ \\
\hline $\begin{array}{l}\text { History of CVD } \\
\text { Relationship }\end{array}$ & $27(10.8 \%)$ \\
Father & $7(20 \%)$ \\
Mother & $11(31.4 \%)$ \\
Brother & $13(37.1 \%)$ \\
Sister & $4(11.4 \%)$ \\
Age at Diagnosis of CVD & $47.3 \pm 16.8$ \\
Died of CVD & $11(50 \%)$ \\
Age at Death from CVD & $66.4 \pm 9.1$ \\
\hline
\end{tabular}


Table 5 Prevalence of CVD Risk Factors Between Genders

\begin{tabular}{llll}
\hline CVD Risk Factor & Men & Women & P-value \\
\hline Hypertension & $36(72 \%)$ & $144(72 \%)$ & 0.969 \\
Dyslipidemia & $22(44 \%)$ & $131(65.5 \%)$ & $\mathbf{0 . 0 0 7}$ \\
Diabetes & $38(76 \%)$ & $134(67 \%)$ & 0.250 \\
Smoking & $7(14 \%)$ & $10(5 \%)$ & 0.432 \\
Unhealthy Diet & $21(42 \%)$ & $116(58 \%)$ & $\mathbf{0 . 0 3 4}$ \\
Overweight & $20(40 \%)$ & $113(56.5 \%)$ & $\mathbf{0 . 0 1 8}$ \\
Physical Inactivity & $43(86 \%)$ & $172(86 \%)$ & 0.970 \\
High Blood Cholesterol & $27(54 \%)$ & $152(76 \%)$ & $\mathbf{0 . 0 0 2}$ \\
\hline
\end{tabular}

\section{Discussion}

CVD is the primary cause of death worldwide [3]. In developing countries, the prevalence of deaths related to CVD is expected to increase from $28.9 \%$ in 1990 to $36.3 \%$ by 2020 [22]. CVD is an increasing health concern, especially in the Middle East and the Gulf Council Countries [23, 24], which includes the KSA [12]. The ACE Saudi Arabia study reported a considerable increase in the prevalence of cardiovascular risk factors [12] and a significant increase in the proportion of patients with poor overall control of modifiable risk factors [25]. The urban population of KSA has increased significantly during recent decades, and it is expected to double in the next few years due to lifestyle changes [26, 27]. Within our study population, there was high mean waste circumference; unhealthy diet and a high-level of inactivity; a significantly higher prevalence of key risk factors in women compared with men; and an association between dyslipidemia and other risk factors. We also found that, although our study subjects were selected because they were at high risk of CVD, many did not perceive themselves to be at elevated risk.

Initial prevention, early detection, and robust healthpromotion strategies have all been successful in lowering the global burden of CVD $[6,28]$. The WHO has identified nine major contributing risk factors for CVD (tobacco smoking, saturated lipids, self-reported hypertension and diabetes, obesity, diet, physical activity, excessive alcohol consumption, and psychosocial factors such as stress), which, in combination, account for $90.4 \%$ of the population-attributable risk of an acute myocardial infarction [29]. The present study of 250 patients attending a General Practice clinic in King Abdul-Aziz University Hospital, Jeddah, KSA, focused on the prevalence of six cardiovascular risk factors. In this sample, we determined a current tobacco smoking prevalence of only $6.8 \%$. The majority of the sample (88\%) had never smoked tobacco, which suggests that as a risk factor for development of CVD, smoking is less of an issue in KSA than in other parts of the world [30].

A high prevalence of dyslipidemia (61.2\%) and hypertension (72\%) was notable in this sample. In contrast, the prevalence of dyslipidemia $(71.1 \%)$ was found to be higher than that of hypertension (43.9\%) in a Nigerian study [22]; the level of obesity was also high. Ahmed et al. reported that almost $50 \%$ of all patients in their study in the KSA had three or more modifiable risk factors for CVD (diabetes, hypertension, smoking, dyslipidemia, obesity [BMI $\left.\geq 30 \mathrm{~kg} / \mathrm{m}^{2}\right]$, or abdominal obesity) [12]. The main risk factors in that sample were dyslipidemia (68.8\%), followed by hypertension (41.8\%), and diabetes $(25.0 \%)$ [12]. Similar results were reported in the study by Alsheikh-Ali et al., in which the prevalence rates of dyslipidemia (70\%) and abdominal obesity $(68 \%)$ were higher than those of hypertension $(43 \%)$ and diabetes (25\%) [31]. The majority of outpatients $(92 \%)$ had at least one modifiable cardiovascular risk factor, $74 \%$ had more than one risk factor, and over half (53\%) had three or more risk factors [31]. However, in our study, hypertension and diabetes mellitus were slightly more prevalent risk factors than dyslipidemia, affecting twothirds of the patients.

In the present study, the mean waist circumference of the sample was $101.6 \pm 14.1 \mathrm{~cm}$. This is a significant cause for concern, since such large individuals are at very high risk of developing CVD, especially when they have several other risk factors present. The prevalence of

Table 6 Differences in CVD Risk Factors among Patients with Hypertension, Dyslipidemia, and Diabetes

\begin{tabular}{|c|c|c|c|c|c|c|c|c|c|}
\hline \multirow[t]{2}{*}{ CVD Risk Factor } & \multicolumn{3}{|c|}{ Patients with Hypertension } & \multicolumn{3}{|c|}{ Patients with Dyslipidemia } & \multicolumn{3}{|c|}{ Patients with Diabetes } \\
\hline & Yes & No & $P$-value & Yes & No & P-value & $\overline{\text { Yes }}$ & No & $P$-value \\
\hline Hypertension & - & - & - & $117(76.5 \%)$ & $62(66.0 \%)$ & 0.073 & $114(66.7 \%)$ & $66(86.8 \%)$ & 0.001 \\
\hline Dyslipidemia & $117(65.4 \%)$ & 36 (52.9\%) & 0.481 & - & - & - & $108(63.5 \%)$ & 45 (59.2\%) & 0.519 \\
\hline Diabetes & $114(63.3 \%)$ & 57 (85.1\%) & 0.815 & $108(70.6 \%)$ & $62(66.7 \%)$ & 0.519 & - & - & - \\
\hline Smoking & $12(6.7 \%)$ & $5(7.4 \%)$ & 0.434 & $8(5.2 \%)$ & $9(9.5 \%)$ & 0.351 & $12(7 \%)$ & $4(5.3 \%)$ & 0.669 \\
\hline Unhealthy Diet & 97 (53.9\%) & 39 (57.4\%) & 0.899 & $93(60.8 \%)$ & $43(45.3 \%)$ & 0.015 & 95 (55.2\%) & $40(52.6 \%)$ & 0.860 \\
\hline Overweight & $102(56.7 \%)$ & $31(45.6 \%)$ & 0.152 & 90 (58.8\%) & $42(44.2 \%)$ & 0.018 & $93(54.1 \%)$ & $40(52.6 \%)$ & 0.961 \\
\hline Physical Inactivity & $158(87.8 \%)$ & $56(82.4 \%)$ & 0.573 & $135(88.2 \%)$ & 78 (82.1\%) & 0.162 & $150(87.2 \%)$ & 64 (84.2\%) & 0.553 \\
\hline High Blood Cholesterol & 135 (75\%) & $43(63.2 \%)$ & 0.676 & $150(98 \%)$ & 27 (28.4\%) & 0.000 & $125(72.7 \%)$ & $54(71.1 \%)$ & 0.749 \\
\hline
\end{tabular}


obesity, as defined by waist circumference, was also high $(68 \%)$ in the study by Alsheikh-Ali et al. [31]. Such findings might indicate patients' unhealthy nutrition choices or lack of opportunities for exercise. Modifiable extrinsic risk factors for the development of all CVDs are to be found in unhealthy lifestyles, including unhealthy dietary habits, physical inactivity, smoking, and being overweight. These factors result in cardiometabolic risk factors, such as hyperglycemia, dyslipidemia and hypertension [32]. In the current study, $54.8 \%$ of the patients followed an unhealthy diet and $52.0 \%$ were physically inactive. A recent case-control study within KSA demonstrated that sedentary behavior was increasingly associated with risk of CHD [33]. Notably, however, data in Table 3 indicate that more than half of our study population did not believe that they had an increased propensity to CVD, despite the significant risk factors the study population displayed. This may suggest a need for more focused, intelligent and strong education in the KSA on the CVD-related outcomes of factors such as obesity, hypertension, poor diet, lack of exercise and diabetes.

Several studies have reported gender differences in acute coronary syndrome (ACS) with respect to its presentation, diagnosis, clinical management and outcomes. The results of some studies have found that women have higher mortality rates than men; however, gender was not found to be a factor related to the presentation or mortality of patients with ACS in other studies [3, 34]. Several studies have reported a relationship between ACS and gender among Middle Eastern patients [12, 35]. Studies by Mehio Sibai et al., DeNicola et al. and Alshaikh et al. reported high prevalence of obesity among women in oil-rich countries, with the latter two focusing on the KSA, resulting from increasing intake of calories, animal fat and protein, and limitations on physical activity [10, 36, 37]. Our sample was largely comprised of older women who had significantly higher likelihood of dyslipidemia $(p=0.007)$, unhealthy diet $(p=0.034)$, being overweight $(p=$ $0.018)$, and high blood cholesterol $(\mathrm{p}=0.007)$ compared with men in the sample. The majority of these women did relatively little exercise or were unable to do so. Gender-specific prevention programs in the KSA should be considered to more appropriately target at-risk individuals, in order to reduce preventable morbidity and mortality associated with CVDs. Interventions to reduce patient risk in our sample could include changes in drug treatment (including drug(s) used and dosages), education about lifestyle factors, improved diet, and exercise.

Our study does have several limitations. This was a relatively small, single-center cross-sectional study, which may be susceptible to recall bias. Furthermore, the inclusion criteria may not be broadly representative of those at risk of developing CHD. Finally, we did not collect data on socioeconomic status, which would potentially focus prevention efforts in areas where they are most needed.

\section{Conclusion}

Our study presents novel findings in comparison to previous studies within the KSA. Women were more likely to have CVD risk factors including dyslipidemia, unhealthy diet, being overweight, and high blood cholesterol compared with their male counterparts in this sample. Gender-specific prevention programs in the KSA should be considered to more appropriately target at-risk individuals, in order to reduce preventable morbidity and mortality associated with CVDs.

\section{Supplementary informations}

Supplementary information accompanies this paper at https://doi.org/10. 1186/s12872-019-1261-6.

Additional file 1. Description: Questionnaire.

Abbreviations

CHD: Coronary heart disease; CVDs: Cardiovascular diseases; KAUH: King Abdulaziz University hospital; KSA: Kingdom of Saudi Arabia; WHO: World health organization

\section{Acknowledgments}

None.

\section{Authors' contributions}

RA designed the study, and contributed to data analysis, interpretation of the results and manuscript writing. $\mathrm{NA}, \mathrm{HG}, \mathrm{BB}, \mathrm{AA} 1$, and $\mathrm{AA} 2$ collected, analyzed and interpreted the data. All authors have seen and approved the final version of the manuscript being submitted. The article is the authors' original work, has not received prior publication, and is not under consideration for publication elsewhere.

\section{Funding}

None.

Availability of data and materials

The datasets used and/or analyzed during the current study are available from the corresponding author on reasonable request.

Ethics approval and consent to participate

This study was approved by the Biomedical Ethics Committee of King Abdulaziz University (Reference No. 322-17). Written consent was obtained from all participants prior to the interview.

Consent for publication

Not applicable.

Competing interests

The authors declare that they have no competing interests.

Received: 18 June 2019 Accepted: 15 November 2019

Published online: 27 November 2019

References

1. Organization WH. Cardiovascular diseases (CVDs) 2017 [Available from: https://www.who.int/news-room/fact-sheets/detail/cardiovascular-diseases(cvds). Accessed 21 Aug 2017.

2. Hajar R. Framingham contribution to cardiovascular disease. Heart views: the official journal of the Gulf Heart Association. 2016;17(2):78. 
3. Khesroh AA, Al-Roumi F, Al-Zakwani I, Attur S, Rashed W, Zubaid M. Gender differences among patients with acute coronary syndrome in the Middle East. Heart views: the official journal of the Gulf Heart Association. 2017; 18(3):77.

4. Organization WH. Cardiovascular disease. 2018

5. Organization WH. Cardiovascular Diseases (CVDs). Fact Sheet September 2017. [Available from: https://www.who.int/news-room/fact-sheets/detail/ cardiovascular-diseases-(cvds). Accessed 21 Aug 2017.

6. Mensah GA, Wei GS, Sorlie PD, Fine LJ, Rosenberg Y, Kaufmann PG, et al. Decline in cardiovascular mortality: possible causes and implications. Circ Res. 2017;120(2):366-80.

7. Organization WH. Cardiovascular diseases (CVDs) Fact sheet. 2017. 2018.

8. Mendis S, Puska P, Norrving B, Organization WH. Global atlas on cardiovascular disease prevention and control: Geneva: World Health Organization; 2011.

9. Mathers CD, Loncar D. Projections of global mortality and burden of disease from 2002 to 2030. PLoS Med. 2006;3(11):e442.

10. DeNicola E, Aburizaiza OS, Siddique A, Khwaja H, Carpenter DO. Obesity and public health in the Kingdom of Saudi Arabia. Rev Environ Health. 2015; 30(3):191-205

11. Kumosani TA, Alama MN, lyer A. Cardiovascular diseases in Saudi Arabia. Prime Res Med. 2011;1:1-6.

12. Ahmed AM, Hersi A, Mashhoud W, Arafah MR, Abreu PC, Al Rowaily MA, et al. Cardiovascular risk factors burden in Saudi Arabia: the Africa Middle East cardiovascular epidemiological (ACE) study. J Saudi Heart Assoc. 2017 29(4):235-43.

13. Alhomaidan HT. PRIMARY PREVENTION OF CORONARY HEART DISEASE (CHD) IN SAUDI ARABIA: MEETING THE CHALLENGE.

14. Al-Kadi A, Malik AM, Mansour AE. Rising incidence of obesity in Saudi residents. A threatening challenge for the surgeons. Int J Health Sci. 2018; 12(1):45.

15. Hadlaq EM, Faraj Z, Al FG, Al FO, Abuabat M, Awan K. Early screening of diabetes and hypertension in primary care dental clinics at King Saud University in Riyadh, Kingdom of Saudi Arabia. J Contemp Dent Pract. 2017; 18(8):652-9

16. Fox CS, Golden SH, Anderson C, Bray GA, Burke LE, De Boer IH, et al. Update on prevention of cardiovascular disease in adults with type 2 diabetes mellitus in light of recent evidence: a scientific statement from the American Heart Association and the American Diabetes Association. Circulation. 2015:132(8):691-718.

17. Teo KK, Dokainish H. Effective Management of Cardiovascular Risk Factors_are we Doing Enough? Can J Cardiol. 2017;33(3):300-2.

18. Organization WH. Noncommunicable Diseases. Fact Sheet. 1st June 2018 [Available from: https://www.who.int/news-room/fact-sheets/detail/ noncommunicable-diseases. Accessed 21 Aug 2017.

19. Stewart J, Manmathan G, Wilkinson P. Primary prevention of cardiovascular disease: a review of contemporary guidance and literature. JRSM Cardiovasc Dis. 2017;6:2048004016687211.

20. Feigin $\mathrm{VL}$, Norrving B, Mensah GA. Primary prevention of cardiovascular disease through population-wide motivational strategies: insights from using smartphones in stroke prevention. BMJ Glob Health. 2017;2(2): e000306.

21. Kotseva K, Wood D, De Backer G, De Bacquer D, Pyörälä K, Reiner Ž , et al. EUROASPIRE III. Management of cardiovascular risk factors in asymptomatic high-risk patients in general practice: cross-sectional survey in 12 European countries. Eur J Cardiovasc Prev Rehabil. 2010; 17(5):530-40.

22. Ogunmola OJ, Olaifa AO, Oladapo OO, Babatunde OA. Prevalence of cardiovascular risk factors among adults without obvious cardiovascular disease in a rural community in Ekiti state, Southwest Nigeria. BMC Cardiovasc Disord. 2013;13(1):89.

23. Aljefree N, Ahmed F. Prevalence of cardiovascular disease and associated risk factors among adult population in the Gulf region: a systematic review. Advances in Public Health. 2015;2015.

24. Kalaf H, AlMesned A, Soomro T, Lasheen W, Ewid M, Al-Mohaimeed AA. Cardiovascular disease risk profile among young Saudi women of Al-Qassim, Saudi Arabia: a cross-sectional study. Int J Health Sci. 2016;10(1):29.

25. Lucero AA, Lambrick DM, Faulkner JA, Fryer S, Tarrant MA, Poudevigne M, et al. Modifiable cardiovascular disease risk factors among indigenous populations. Adv Prev Med. 2014;2014.
26. Al-Hazzaa HM. Physical inactivity in Saudi Arabia revisited: a systematic review of inactivity prevalence and perceived barriers to active living. Int $J$ Health Sci. 2018;12(6):50.

27. Abdelatti $\mathrm{H}$, Elhadary $Y$, Babiker AA. Nature and trend of urban growth in Saudi Arabia: the case of Al-Ahsa Province-eastern region. Resources and Environment. 2017;7(3):69-80.

28. Onyemelukwe GC, Ogunfowokan O, Mbakwem A, Alao AK, Soroh K, Omorodion O, et al. Cardiovascular risk factors in adult general out-patient clinics in Nigeria: a country analysis of the Africa and Middle East cardiovascular epidemiological (ACE) study. Afr Health Sci. 2017;17(4):1070-81.

29. Jennings C, Astin F. A multidisciplinary approach to prevention. Eur J Prev Cardiol. 2017;24(3_suppl):77-87.

30. Lu L, Mackay DF, Pell JP. Secondhand smoke exposure and risk of incident peripheral arterial disease and mortality: a Scotland-wide retrospective cohort study of 4045 non-smokers with cotinine measurement. BMC Public Health. 2018;18(1):348.

31. Alsheikh-Ali AA, Omar MI, Raal FJ, Rashed W, Hamoui O, Kane A, et al. Cardiovascular risk factor burden in Africa and the middle east: the Africa middle east cardiovascular epidemiological (ACE) study. PLoS One. 2014; 9(8):e102830.

32. Siren $\mathrm{R}$, Eriksson JG, Vanhanen $\mathrm{H}$. Observed changes in cardiovascular risk factors among high-risk middle-aged men who received lifestyle counselling: a 5-year follow-up. Scand J Prim Health Care. 2016;34(4):336-42.

33. Al-Zoughool M, Al-Ahmari $\mathrm{H}$, Khan A. Patterns of physical activity and the risk of coronary heart disease: a pilot study. Int J Environ Res Public Health. 2018;15(4):778.

34. Mosca L, Barrett-Connor E, Kass WN. Sex/gender differences in cardiovascular disease prevention: what a difference a decade makes. Circulation. 2011;124(19):2145-54

35. Zubaid M, Thani KB, Rashed W, Alsheikh-Ali A, Alrawahi N, Ridha M, et al. Design and rationale of gulf locals with acute coronary syndrome events (Gulf Coast) registry. The open cardiovascular medicine journal. 2014;8:88.

36. Sibai AM, Nasreddine L, Mokdad AH, Adra N, Tabet M, Hwalla N. Nutrition transition and cardiovascular disease risk factors in Middle East and North Africa countries: reviewing the evidence. Ann Nutr Metab. 2010;57(3-4):193-203.

37. Alshaikh MK, Filippidis FT, Baldove JP, Majeed A, Rawaf S. Women in Saudi Arabia and the prevalence of cardiovascular risk factors: a systematic review. J Environ Public Health. 2016;2016.

\section{Publisher's Note}

Springer Nature remains neutral with regard to jurisdictional claims in published maps and institutional affiliations.
Ready to submit your research? Choose BMC and benefit from:

- fast, convenient online submission

- thorough peer review by experienced researchers in your field

- rapid publication on acceptance

- support for research data, including large and complex data types

- gold Open Access which fosters wider collaboration and increased citations

- maximum visibility for your research: over $100 \mathrm{M}$ website views per year

At BMC, research is always in progress.

Learn more biomedcentral.com/submissions 